\title{
Lipid profile in normal pregnancy
}

Accepted: 8/12/2011

Sinan Butrus Garabet *

\section{Abstract}

Background and objectives: Normal pregnancy is associated with disturbances in various biochemical values. The purpose of this study was to determine whether normal pregnancy is associated with any abnormalities of lipid profile .

Methods: This prospective study evaluated lipid profile in 45 primigravid women during normal gestation (in the first \& third trimester) and in 30 non-pregnant age matched controls for the period of December 2008- May 2009

Results: Pregnant women exhibit a significant increase in mean serum cholesterol concentration 226.5 (S.D.42.2) $\mathrm{mg} / \mathrm{dL}$ in the first trimester when compared with non-pregnant controls $167.9(27.7) \mathrm{mg} / \mathrm{DI}$. The serum cholesterol increased significantly throughout gestation to a mean of $316.6(54.8) \mathrm{mg} / \mathrm{dL}$ in the third trimester compared with the first trimester. Triglyceride panel in the first trimester had been similar to those of controls. However, by the third trimester the mean triglyceride concentration had revealed a double value of 227.7 (47.4) mg/dL; compared with the first trimester. There was no significant difference in the LDL level in first trimester when compared to control group. Nevertheless, it increased significantly, from $93.6(11.9) \mathrm{mg} / \mathrm{dL}$ during the first trimester to $178.6(18.5) \mathrm{mg} /$ $\mathrm{dL}$ in the third trimester

Conclusion: Atherogenic lipid profile develops during normal gestation. The future significance of these changes remains to be determined. They may have important implications for the mother and fetus

Keywords: Normal pregnancy, cholesterol, low density lipoprotein, triglycerides.

\section{Introduction}

Low-density lipoprotein (LDL) is an important risk factor for coronary heart disease, as it can be oxidized, taken up by macrophages, to become engorged and form foam cells. These foam cells often become trapped in the walls of blood vessels and contribute to atherosclerotic plaque formation, initiating endothelial dysfunction and thereby promoting atherogenesis in a variety of ways. ${ }^{1}$ Although high triglyceride concentrations are largely responsible for promoting the formation of LDL particles ${ }^{2}$, both insulin resistance ${ }^{3}$ and oestrogens (in women) play a major role in disturbing lipid profile. Premenopausal women tend to have lower level of LDL and this may be due to the influence of oestrogen, however, some studies ${ }^{4}$ proved that hormone replacement therapy in postmenopausal women seems to promote the formation of LDL laden foam cells. Normal pregnancy is associated with high concentrations of oestrogens and some form of insulin resistance, both may contribute to disturbed lipid profile especially in the latter half of pregnancy. ${ }^{5}$ This effect is exaggerated in preeclampsia, and high levels of LDL have been implicated in the pathogenesis of preeclampsia \& pregnancy induced hypertension. ${ }^{6}$ In the present paper we investigate the changes in lipids profile in a group of normal pregnant women to determine

*Department of Clinical standards \& Guidelines, Kurdistan Higher Council for Medical Specialties, Erbil, Iraq. 
whether a change to a more atherogenic lipid profile is an inevitable consequence of normal pregnancy.

\section{Methods}

Fasting serum lipids (cholesterol, triglyceride\& $L D L$ ) were analyzed prospectively in 45 women with normal pregnancy (in the first \& third trimester), and in 30 agematched non-pregnant controls (21-39 years of age) in the maternity teaching hospital /Erbil city-Kurdistan region- north of Iraq, from December 2008 to May 2009.

12 hours fasting venous blood was sampled and serum separation was carried out by low-speed centrifugation (3000 g for 15 min) then serum lipid profile was assessed using bt $35 \mathrm{i}$ auto analyzer. Pregnant women with hypertension, diabetes mellitus, anemia or any other medical conditions were excluded from this study and those who are on medications apart from those who routinely administer ironfolic acid supplements as part of normal pregnancy prescription. Formal consent was obtained from all candidiates.

\section{Statistics:}

The statistical significance of differences between groups was determined by the unpaired Student's $t$ test, and the level of significance was taken as $\mathrm{P}<0.05$

\section{Results}

The mean serum total cholesterol concentration was significantly higher in the pregnant women during the first trimester [226.5 (S.D. 42.2) $\mathrm{mg} / \mathrm{dL}$ ] than in the control group [167.9 (27.7) mg/dL; $P<0.05]$. Serum cholesterol increased progressively during pregnancy, to a mean concentration of $316.6(54.8) \mathrm{mg} / \mathrm{dL}$ in the third trimester $(P<0.05$ compared with the first trimester). In seven women, serum cholesterol exceeded $348.0 \mathrm{mg} / \mathrm{dL}$ during the third trimester. On average, mean cholesterol increased by $40 \%$ during gestation. Triglycerideconcentrations in the first trimester were almost similar to the normal range observed in the non-pregnant controls.
By contrast, in the third trimester the figure was almost doubled [227.7 (47.4) mg/dL; $\mathrm{P}<0.05$ compared with the first trimester]. In nine women, triglyceride concentrations exceeded $309.5 \mathrm{mg} / \mathrm{dL}$ in the third trimester. There was no significant changes in LDL in first trimester when compared with non-pregnant controls, but there was dramatic increase, from 93.6 (S.D. 11.9) mg/ $\mathrm{dL}$ during the first trimester to 178.6 (18.5) $\mathrm{mg} / \mathrm{dL}$ in the third trimester $(\mathrm{P}<0.05 \mathrm{com}$ pared with the first trimester). These change in LDL \& serum triglycerides during pregnancy were closely matched. 
Table 1: Lipid profile in pregnant women compared with non-pregnant controls

\begin{tabular}{lccc} 
Subjects & Total cholesterol $(\mathbf{m g} / \mathbf{d L})$ & Triglyceride $(\mathbf{m g} / \mathbf{d L})$ & LDL $(\mathbf{m g} / \mathbf{d L})$ \\
\hline Controls $\mathrm{N}=30$ & $167.9(27.7)$ & $91.6(16.1)$ & $82.4(8.5)$ \\
First trimester $\mathrm{N}=45$ & $226.5(42.2)^{*}$ & $108.5(26.9)$ & $93.6(11.9)$ \\
Third trimester $\mathrm{N}=45$ & $316.6(54.8)^{* \Omega}$ & $227.7(47.4) * \Omega$ & $178.6(18.5)^{* \Omega}$
\end{tabular}

Values are means (S.D.) for $\mathrm{N}=45$ women in each trimester, and for $\mathrm{N}=30$ controls. ${ }^{*} \mathrm{P}<0.05$ compared with controls, ${ }^{\Omega} \mathrm{P}<0.05$ compared with the first trimester

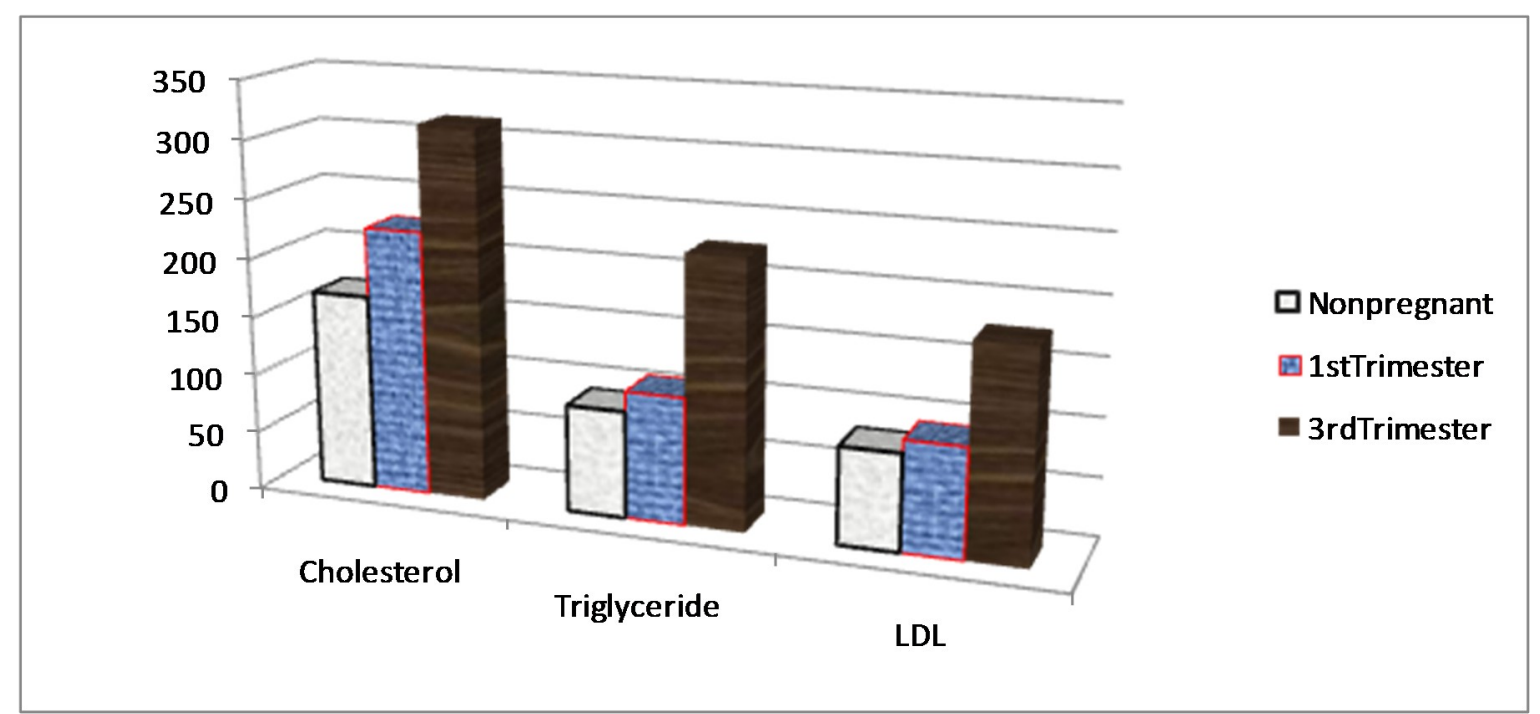

Figure 1: Levels of cholesterol, triglyceride, LDL

\section{Discussion}

The results of this study are almost consistent with other studies which revealed a significant increase of serum lipids during the course of normal pregnancy; serum cholesterol and triglycerides have been found in many studies to increase by more than $25 \%$ and $100 \%$ respectively. ${ }^{7-9}$ Many studies have attributed the increment in serum lipids concentrations to be positively correlated with the increase of oestrogens, progesterone, human placental lactogen, insulin levels and insulin resistance throughout the whole period of gestation..$^{7-9}$ Although the significance of these changes aare uncertain, they are possibly related to the maintenance of nutrient fuel to the mother and fetus. ${ }^{10-12}$
The triglycerides on the other extreme are important sources of lipid fractions, \& are major determinant of LDL, accounting for $40-60 \%$ of the variability of this fraction in the plasma. ${ }^{13,14}$ Those LDL particles, at higher concentrations precipitate \& penetrate the arterial intima, to be oxidized \& engulfed by macrophages to create foam cells, initiating the process of atherogenesis. This may explain their identification as an independent risk factor for coronary heart disease..$^{15-17}$ Pregnancy provides a remarkable opportunity to observe changes in LDL dysregulation in relation to a progressive increase in triglycerides. This study clearly demonstrated as the pregnancy progresses plasma triglycerides increased, paralleled by a dramatic increase in the LDL, suggesting an atherogenic lipid 
profile change. Several factors during gestation may promote this change. For example, pregnancy is associated with a progressive increase in oestrogen level; in addition, although fasting insulin levels was normal during the first half of pregnancy, it rose after week 23 only to reach a plateau at week $31 .^{18,19}$ Relative insulin resistance is a feature of late gestation and this may also contribute to abnormal lipid profile, since insulin normally is lipidogenic ${ }^{19}$ The changes in lipid profile observed during pregnancy may be of potential importance for a woman's long-term health. Elevated serum cholesterol, LDL \& triglycerides are classified as an independent risk factor for future coronary heart disease in women. ${ }^{17-19}$ During pregnancy all women develops a transient hyperlipidaemia and a significant proportion go on to develop hypertension associated with pre-eclampsia, gestational diabetes and maternal obesity. The long-term consequences of these conditions on coronary heart disease are not clear at moment; however, there is an increased prevalence of angina, cholesterol gallstones, diabetes and obesity in postmenopausal women who have had several pregnancies ${ }^{20,22}$ as compared to nulliparous. The change in serum cholesterol during pregnancy is associated with parity so that, for each additional previous pregnancy, a further increase in cholesterol of around $4.5-7 \mathrm{mg} / \mathrm{dL}$ is observed. ${ }^{23}$ Furthermore, it is not clear whether; post partum, serum lipids normalize completely in multiparous women who are at increased risk of cardiovascular disease.

\section{Conclusion}

This study demonstrated that normal pregnancy is associated with a significant increase in cholesterol, LDL and triglycerides. By the third trimester, most women have a lipid profile considered to be highly atherogenic when compared to the nonpregnant state. This represents a transient disturbance which reverts to normal after delivery. The long term consequences of multiple pregnancies on lipid profiles remains to be determined.

\section{References}

1. Campos, H., Genest, J. J., Blijlevens, E. Low density lipoprotein particles size and coronary artery disease. Arteriosclerosis Thromb.1992; 12, $187 \pm 195$

2. Silliman, K., Shore, V. and Forte, T. M. Hypertriglyceridemia during late pregnancy is associated with the formation of small dense lowdensity lipoproteins and the presence of large buoyant high density lipoproteins. Clin. Exp. Metab. 1994; 43, 1035 \pm 1041

3. Tan, K. C. B., Cooper, M. B., Eddie Ling, K. L. Fasting and postprandial determinants for the occurrence of small dense LDL species in noninsulin- dependent diabetic patients with and without hypertriglyceridaemia: the involvement of insulin, insulin precursor species and insulin resistance. Atherosclerosis 1995; 113, 273 \pm 287

4. Rajman, I., Lip, G. H., Cramb, R. Adverse change in low-density lipoprotein subfractions profle with oestrogen-only hormone replacement therapy $Q$. J. Med. 1996; 89, 771 \pm 778

5. Alvarez, J., Montelongo, A., Iglesias, A. and Lasuncion, M. Longitudinal study on lipoprotein profile, high density lipoprotein subclass, and postheparin lipases during gestation in women. J. Lipid Res. 1996; 37, 299 \pm 308

6 .Sanchez SE, Williams MA et al, A case-control study of oxidized low density lipoproteins and preeclampsia risk Gynecol Endocrinol. 2005 Oct; 21(4):193-9

7. Smolarczyk R, Romejko E: The effect of total estrogens and lactogen hormone on lipid metabolism in women during normal pregnancy. Ginekol Pol; 1996 Sep;67(9):438-42

8. Darmady, J. and Postle, A. Lipid metabolism in pregnancy. Br. J. Obstet. Gynaecol. 1982; 89, $211 \pm 215$

9. Chiang, A.-N. A., Yang,M.-L., Hung, J.-H. Alterations of serum lipid levels and their biological relevances during and after pregnancy. Life Sci. 1995; 56, 2367 \pm 2375

10. Desoye, G., Schweditsch, M., Pfeiffer, K. and Zechner, R. Correlation of hormones with lipid and lipoprotein levels during normal pregnancy and postpartum. J. Clin. Endocrinol. Metab. 1987; $64,704 \pm 712$

11. Hurt-Camejo, E., Camejo, G., Rosengreen, B. Differential uptake of proteoglycan selected subfractions of LDL by human macrophages. J. Lipid Res. 1990; 31, 1387 \pm 1398

12. Tripathy C, Malik S, Shah P, Lakshmy R, Tripathy $D$ : Serum insulin and lipid profile in normal pregnant and pregnancy-induced hypertensive women from North India. Aust N Z J Obstet Gynaecol; 1999 Aug;39(3):321-3 
13. Griffn, B., Freeman, D., Tait, G. Role of plasma triglyceride in the regulation of plasma low density lipoprotein (LDL) subfractions : relative contribution of small, dense LDL to coronary heart disease risk. Atherosclerosis 1994; 106, 241 \pm 253

14. Herrera, E., Lasuncion, M. A., Gomez-Coronado, D., Lopez-Luna, Role of lipoprotein lipase activity on lipoprotein metabolism and the fate of circulating triglycerides in pregnancy. Am. J. Obstet. Gynecol. 1988; 158, 1575 1583

15. Coresh, J., Kwiterovich, P. O., Smith, H. H. and Bachorik, P. S. Association of plasma triglyceride concentration and LDL particle diameter, density and chemical composition with premature coronary artery disease in men and women. Clin. Sci. 1995; 88, 311 \pm 318

16. Bengtsson, C., Rybo, G. and Westerberg, H. Number of pregnancies, use of oral contraceptives and menopausal age in women with ischemic heart disease, compared to a population sample of women Acta Med. Scand. Suppl. 1973; $549,75 \pm 81$

17. Gardner, C. D., Fortmann, S. P. and Krauss, R. M. Association of small, dense low-density lipoprotein particles with the incidence of coronary heart disease in men and women. J. Am. Med. Assoc. 1996; 276, 875 \pm 881

18. Mancini, M., Steiner, G., Betteridge, D. J. Acquired (secondary) forms of hypertriglyceridemia. Am. J. Cardiol. 1991; 68, 17A $\pm 21 \mathrm{~A}$

19. Bartha JL, Comino-Delgado R: Insulin-sensitivity index and carbohydrate and lipid metabolism in gestational diabetes. J Reprod Med; 2000 Mar;45 (3):185-9

20. Kritz- Silverstein, D.,Barrett-Connor, E. and Wingard, D. L. The relationship between multiparity and lipoprotein levels in older women. J. Clin. Epidemiol. 1992; 45, 761 \pm 767

21. Igweh JC, Nwagha IU, Okaro JM: The effects of menopause on the serum lipid profile of normal females of South East Nigeria. Niger J Physiol Sci; 2005 Jun-Dec;20(1-2):48-53

22. Walsh, B. W., Schiff, I., Rosner, B. Effects of postmenopausal estrogen on the concentrations and metabolism of plasma lipoproteins. N. Engl. J. Med. (1991) 325, 1196 \pm 2004

23. Sirikulchayanonta C, Singsurapap W, Phuapradit W: The effect of parity on lipid profile in normal pregnant women. J Med Assoc Thai; 2000 Mar;83 Suppl 1:S141-5 